\title{
Improved Energy Conversion Process With Coupling Induction Motors And Invastigate Unbalanced Operation With Definition Of The Voltage Unbalance
}

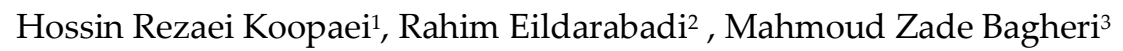 \\ ${ }^{1}$ Master of elctrical engineearing, Electrical department, azad univercity of Yasouj Iran \\ 2 Faculty of elctrical engineearing, Electrical department, Sabzevar univercity, Iran \\ ${ }^{3}$ Faculty of elctrical engineearing, Electrical department, azad univercity of Yasouj Iran
}

\begin{abstract}
This paper assesses Voltage unbalance study as one of power quality issues which is especially effected distribution voltages and is noteworthy. however it is possible that voltage in level of producing and transmission be balanced but this voltages in level of distribution can go out of balance and be unbalanced which is because of unbalanced systems, unequal impedances and lack of appropriate and balanced distribution of one phase loads in distribution systems occurs. In this thesis operation of steady state machine conjunction (Induction motor) under unbalanced voltage will be evaluated. Induction motors in small sizes attach as coupled and will be used instead of big sized induction motors, which is proper for improved electromagnetic systems and more efficient energy conversion mechanism in both symmetric and asymmetric states. Two coupled induction motors can have the same or different rates mechanically. This thesis will analyze coupled machinery using symmetric elements and MATLAB software. Definition of unbalance voltage is used by CVUF factor (complex voltage unbalance factor). Induction motors coupling with DC motors (direct current) is analyzed and coupling effect in electromagnetic torque in all system is studied and comparing of unbalanced voltage on standalone and coupled machines is demonstrateed. The purpose of such comparing is finding the best states in balanced and unbalanced working, also this thesis evaluates the effect of induction motors connection as coupling in energy conversion process.
\end{abstract}

Keywords: induction motor, DC motors, unbalanced voltage, energy conversion 


\section{Introduction}

$\mathrm{T}$ he induction machine is as considered one of the most popular machines in the industry; it could be used properly to save the energy consumed and to advance the efficiency [1,2]. Thus, this paper studies the use of cascading small sizes induction machines instead of one big size induction machine to promote the electromagnetic system and the energy conversion mechanism [3]. The electromagnetic forces act between the rotor and the stator where the magnetic flux density is different in the big size induction machines than the small sizes induction machines attached in cascade wherein the rating summation thereof is the same rating of the big size induction machine [4].

The cascaded induction machines herein, deemed to be two coupled induction machines, are cascaded on the same shaft and feed the same load. The motor coupling is either a magnetic coupling or electrical coupling. Although the same torque is transferred to the load, the energy conversion progression is changed and the efficiency is different.

Voltage unbalance is a power quality issue, it is a common phenomenon found in a 3-phase power system. Although the 3-phase voltage supply is balanced in both magnitude and phaseangle at the generation and transmission level, the voltage at the load terminal and utilization side could become unbalanced [5e7]. It is practically impossible to obviate such unbalance due to the uneven distribution of single-phase loads in the three-phase supply system, asymmetric transmission line and transformer winding impedances. Such condition has severe impacts on the efficiencyof an induction machine [8]. This machine can tolerate a low degree of voltage unbalance, so the unbalance could be derated if it is excessive [9]. The voltage unbalance can increase stator and rotor losses in the induction machine, rise windings temperature, reduce the insulation life caused by overheating, and de-rate its output power, so it cannot tolerate the extra heating arising from the unbalanced voltage supply. It is worth mentioning that the unbalanced conditions are two conditions; at over-voltage and at under-voltage [10]. From this point of view, the paper studies replacing one big size induction machine with small size induction machines to reach the best efficiency throughout the unbalanced state.

\section{Quantification of CVUF (complex voltage unbalance factor)}

VU (voltage unbalance) has been examined by some researches explained in Ref. [11]. In most previous studies, the approach of evaluating the degree of unbalanced voltage is based on either NEMA (National Electrical Manufactures Association) standard or IEC (International Electromechanical Commission) quantification. Both the NEMA and the IEC quantifications are only considering the magnitude of the voltage unbalance to describe the degree of unbalanced voltage. The 3-phase voltage supply has not only magnitude but also phase-angle that gives contribution to the voltage unbalance. Hence, both the quantifications lead to a comparatively large error in predicting the performance of the induction machine.

A more precise approach in predicting the efficiency of an induction machine working with unbalanced 3-phase voltage is by using the complex quantity to specify the degree of voltage unbalance. This quantification was recently known as the complex unbalance voltage factor and is used as CVUF in the most recent literature [11]. So, the CVUF is an extension of the IEC quantification which consists of magnitude and angle of the voltage unbalance.

Study of inductions machine operating with unbalanced voltage supply using are done in this paper by using symmetrical component approach and by MATLAB/Simulink modeling software .

(1) $V_{a b}=V_{a}-V_{b}$

(2) $V_{b c}=V_{b}-V_{c}$

(3) $V_{c a}=V_{c}-V_{a}$

(4) $V_{s 1}=\frac{1}{3}\left(a V_{a b} * a^{2} V_{b c} * V_{c a}\right)$ 
(5) $V_{s 2}=\frac{1}{3}\left(a^{2} V_{a b} * a V_{b c} * V_{c a}\right)$

The CVUF is defined as displayed Eq (6), where $K_{u}$ is the magnitude and $q_{u}$ is the angle of the CVUF.

(6) $K_{u}=\frac{V_{s 2}}{V_{s 1}}=k_{u}<\theta$

If the ratio of line-voltages is defined by:

(7) $V_{a b}: V_{b c}: V_{c a}=1: X: Y$

Then, the relation between $\left(\mathrm{K}_{\mathrm{u}} ; q_{\mathrm{u}}\right)$ and $(\mathrm{X}, \mathrm{Y})$ is:

(8) $X=\frac{1+K_{u}}{a^{2}+a K_{u}}, Y=\frac{a+a^{2} K_{u}}{a^{2}+a K_{u}}$

where $K_{u}$ and $q_{u}$ are the magnitude and angle of CVUF of the phase voltage respectively. The angle, $q_{u}$ indicates the angle by which $V_{s 2}$ leads the $\mathrm{V}_{\mathrm{s} 1}$, and it is an important parameter to decide the pattern of voltage under different condition of unbalance, whereas $\mathrm{k}_{\mathrm{u}}$ is the measurement of the intensity of severity. Normally the $\mathrm{V}_{\mathrm{s} 1}$ is very close to unity in per unit $\mathrm{k}_{\mathrm{u}}$ will be very close to $\mathrm{V}_{\mathrm{s} 2}$.

Fig. 1 illustrates the complex voltage unbalance factor (CVUF) diagram. It was obtained from using Equations (7) and (8). The relation between $\left(\mathrm{K}_{\mathrm{u}} ; \mathrm{qu}_{\mathrm{u}}\right)$ and $(\mathrm{X}, \mathrm{Y})$ with factor $K_{u}$ and varies $q_{u}$ from (0e360), the loci displayed in ( $X$ Y)plane looks like ellipse. Using the relation between $\left(K_{u}, q_{u}\right)$ and $(X, Y)$ with factor $q_{u}$ and varies $K_{u}$ the loci displayed in (X Y)plane looks like straight line.

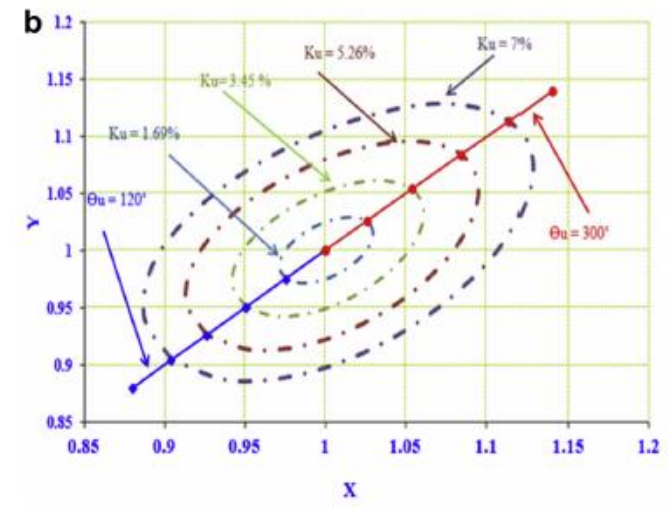

Figur1 1: Complex voltage unbalance factor (CVUF) diagram.

\section{Torque/slip specification}

The symmetrical component theory approach is used to analyze the situation of induction machine under such conditions. MATLAB/ Simulink software is employed for computer simulation.

Fig. 2 illustrates the difference between the torque/slip specification for $50 \mathrm{hp}(37,300 \mathrm{~W})$ induction machine. The impact of the balanced and unbalanced supply voltage is displayed. It is noted that the torque decreases for different rates of the unbalanced voltage that can be explained by the unbalance voltage produce negative sequence torque decreases the produced torque

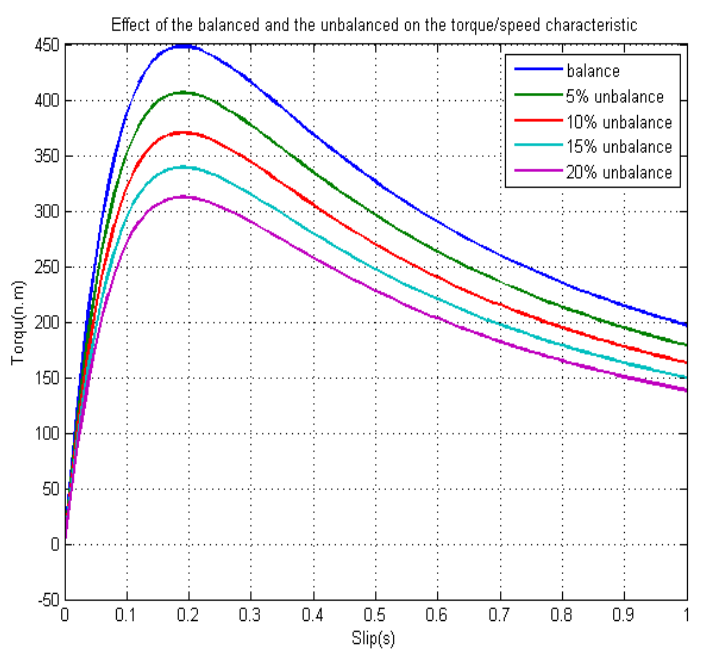

Figur1 2: Effect of the balanced and the unbalanced on the torque/speed characteristic

\section{Torque/slip specification}

In this section, two induction machines are attached in cascade either through mechanical coupling or electrical coupling. The rating of each one is $25 \mathrm{hp}(18,650 \mathrm{~W})$, so the entire rating of the set is $50 \mathrm{hp}(37,300 \mathrm{~W})$ which equals the rating of one big standalone induction machine for comparison purpose. The parameters of the motors are different, so different specifications are expected. In Fig. 3 the torque speed specification of the two coupled machines is higher in the balanced state.

Also in Figs. 4 From the illustrated curves, it is obvious that exerting unbalance voltages to the 3 phases induction machine decreases its maximum energy conversion rate which is directly proportional to the output torque, and shifts the torque speed specification down which 
forces to de-rate the motor to avoid the machine burnout.

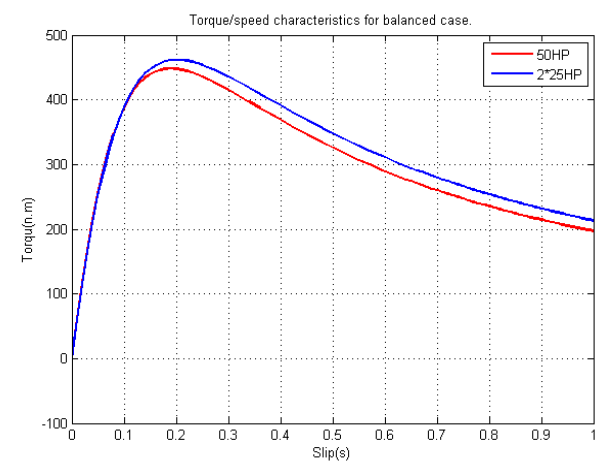

Figur1 3: Torque/speed specifications for balanced condition

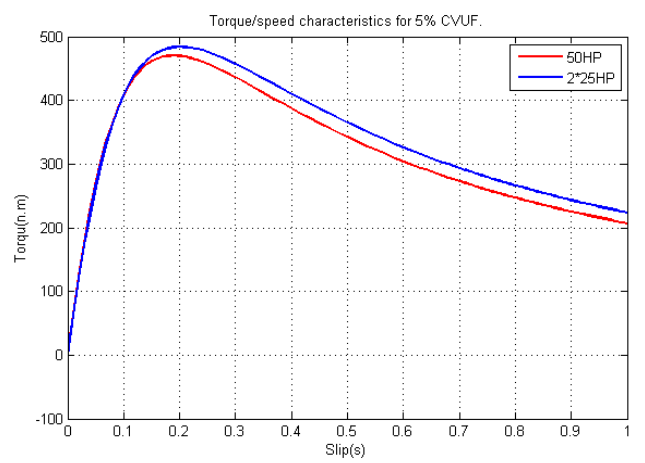

Figur1 4: Torque/speed specifications for $5 \%$ CVUF.

\section{Cascading the induction machine with DC motor}

The torque/speed specification of any induction machine has a general fixed shape. Hence, to promote the electromagnetic system and the energy conversion process, the induction machine must be cascaded with another type of electrical motors to obtain a new electromagnetic system that has better energy conversion mechanism. In this section, 2 conditions of cascading induction machine with DC machine are analyzed as follows:

First condition: Cascaded $25 \mathrm{hp}(18,650 \mathrm{~W})$ induction machine with $5 \mathrm{hp}$ (3730 W) DC machine .

Fig. 5 illustrates the torque/speed specification of the $25 \mathrm{hp}(18,650 \mathrm{~W})$ induction machine and also the torque/speed specification of $5 \mathrm{hp}(3730 \mathrm{~W})$ separately excited DC machine. These two machines are attached in cascade and the produced torque/speed specification is compared with one big single induction machine and all are illustrated in Fig. 5.
Several advancements in the torque/speed specification of the $30 \mathrm{hp}(22,380 \mathrm{~W})$ set (induction machine cascaded with DC machine) are noticed, the starting torque and the maximum torque are significantly increased. Also, the torque for the entire speed range increased due to the cascading mechanism.

Second condition: Cascaded 3 machines together, $15 \mathrm{hp}(11,190 \mathrm{~W})$ induction machine with $10 \mathrm{hp}(7460 \mathrm{~W})$ induction machine with 5 hp (3730 W) DC machine.

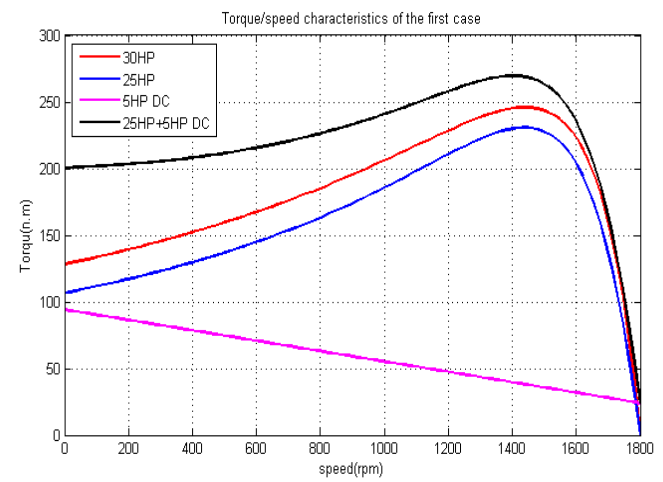

Figur1 5: Torque/speed specifications of the first condition.

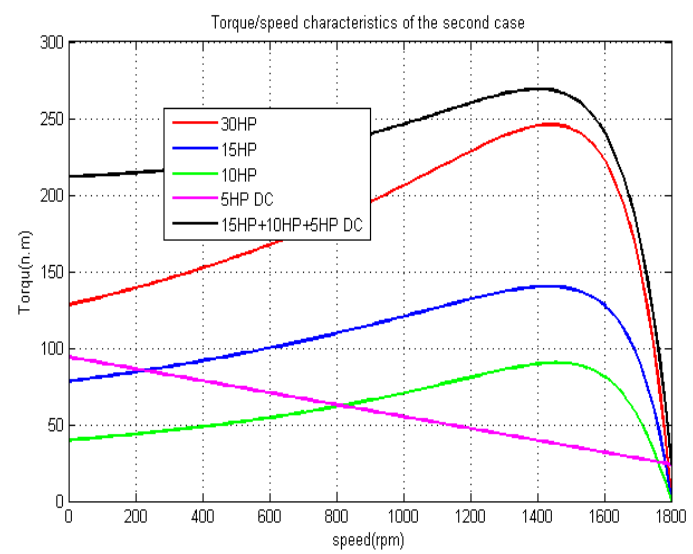

Figur1 6: Torque/speed specifications of the second condition.

\section{Conclusion}

The paper opens a new era for the electrical motors by introducing more advantages of cascading electrical motors. It also introduces further studies of a new concept relates to the electrical motors and more particularly to the induction machines which is the conjunction of a small sizes induction machines in cascade instead of one big size induction machine in 
order to obtain new electromagnetic system that has a better energy conversion mechanism during the balanced and the unbalanced state. The paper uses a precise approach for assessing the efficiency of the induction motors which are supplied via the unbalanced supply. This approach includes the magnitude and angle of the voltage. Different sets of electrical motors, either have the same type or different types, are attached in cascade. The electrodynamics system and the energy conversion both are advanced due to the cascading mechanism. The parameters of the cascaded set of the motors are different than one big standalone mechanism that can give higher torque and better torque/speed specification. The unbalanced supply and its impact on the electrical machine are a power quality issue. The degree of voltage unbalance is a quantity and this paper assesses it precisely by using the magnitude and angle to asses it. The cascaded group has higher starting and maximum torques. Consequently, it has an efficient energy conversion mechanism during the balanced and the unbalanced working. Then, the cascaded induction machine with the DC machine provides more advantages from the set which has higher starting torque and maximum torques. Finally, it is recommended that the concept of cascading the electrical machines is better in the energy conversion mechanism and more efficient during both operation modes: balanced and unbalanced.

\section{References}

Ibrahim Alsofyani, Idris NRN. (2003) "A review on sensorless techniques for sustainable reliability and efficient variable frequency drives of induction motors". Renew Sustain Energy Rev ;24:111e21.

Hasanuzzaman M, Rahim NA, Saidur R, Kazi SN. (2011) "Energy savings and emissions reductions for rewinding and replacement of industrial motor. Energy" ;36(1):233e40. Elsevier.

Mahatoa SN, Singhb SP, Sharmac MP., (2013) "Dynamic behavior of a single-phase selfexcited induction generator using a threephase machine feeding singlephase dynamic load. Int J Electr Power Energy System"; 47:1e12. Elsevier.
Mohd Abdullah Asuhaimi B, Mahmoud Pesaran HA, Khairuddin Azhar B, Jahanshaloo Leila, Shariati Omid (2013) "An overview on doubly fed induction generators" controllers and contributions to wind based electricity. Renew Sustain Energy Rev ;27:692e708. Elsevier.

Pichan M, Rastegar H, Monfared M. (2013) “Two fuzzy-based direct power control strategies for doubly-fed induction generators in wind energy conversion systems. Energy" 51(1):154e62. Elsevier.

Pillay P, Hoftman P, Manyage M. (2002) Derating of induction motors operating with the combination of unbalanced voltages and over or under voltages. IEEE Trans Energy Convers 17(4):485e91

Popa C, Pentiuc R. (2012) "Analysis of a new induction thermal converter for heating. Energy";42(1):81e93. Elsevier.

Roy NK, Pota HR, Mahmud MA, Hossain MJ. (2013) "Key factors affecting voltage oscillations of distribution networks with distributed generation and induction motor loads" Int J Electr Power Energy System;53:515e28. Elsevier.

Sakthivel VP, Subramanian S. (2012) “On-site efficiency evaluation of three-phase induction motor based on particle swarm optimization. Energy";36(3): 1713e20. Elsevier.

Zhang Q, Mclellan BC, Tezuka T, Ishihara KN., (2013) "A methodology for economic and environmental analysis of electric vehicles with different operational conditions. Energy";61(1):118e27. Elsevier. 